\title{
Sebaran Indikasi Air Tanah Terkontaminasi Lindi Di Sekitar Tempat Pembuangan Akhir Sampah Bukit Pinang Kota Samarinda
}
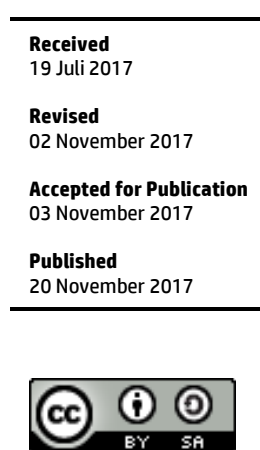

This work is licensed under a Creative Commons Attribution ShareAlike 4.0 International License.

\author{
Lambang Subagiyo ${ }^{1.2}$ Petrus AD Lazar $^{1}$ Sumaryono $^{1}$ \\ ${ }_{1}^{1}$ Program Pascasarjana, Universitas Mulawarman, Kalimantan Timur \\ 2. Program Fisika FKIP Universitas Mulawarman, Kalimantan Timur
}

"E-mail: 1subagiyo@yahoo.com

\begin{abstract}
The final waste disposal site (TPA) Bukit Pinang of Samarinda City applies open dumping method so that it can potentially produce leachate that can pollute the surrounding environment. This study aims to determine the distribution of groundwater contaminated leachate. We used the geoelectric method by analyzing the geological and geomorphological characteristics around the landfill to produce an alleged model of the shallow leached groundwater distribution contaminated around the landfill. The results indicated that there is an indication that shallow groundwater has been contaminated by leachate indicated by the result of measurement of the distribution of resistivity value, the distribution of chargeability value. The contamination indications are located in the northern, eastern and southern parts of the landfill with spreading pattern following the rock layer strike pattern (N $20 \mathrm{E}$ ) and the river flow pattern of the eastern part of the TPA.
\end{abstract}

Key Words: TPA, leachate, geolistric, resistivity.

\begin{abstract}
Abstrak
Tempat penampungan akhir sampah (TPA) Bukit Pinang Kota Samarinda menerapkan metode open dumping sehingga berpotensi menghasilkan lindi yang dapat mencemari lingkungan sekitarnya. Penelitian ini bertujuan untuk mengetahui sebaran air tanah terkontaminasi lindi. Metode yang diimplentasikan adalah metode geolistrik, yaitu dengan cara menganalisis karakteristik geologi dan geomorfologi di sekitar TPA untuk menghasilkan model dugaan sebaran air tanah dangkal terkontaminasi lindi di sekitar TPA tersebut. Hasil penelitian menunjukkan adanya indikasi bahwa air tanah dangkal telah terkontaminasi lindi yang ditunjukan oleh hasil pengukuran sebaran nilai resistivitas, sebaran nilai chargeability. Indikasi kontaminasi tersebut berada pada bagian utara, timur dan selatan TPA dengan pola sebaran mengikuti pola jurus (strike) lapisan batuan (N 20 E) dan pola aliran sungai di bagian timur TPA.
\end{abstract}

Kata Kunci: TPA, lindi, geolistrik, resistivitas.

\section{Pendahuluan}

Metode open dumping dalam pengolahan sampah di TPA merupakan sistem pemrosesan yang sederhana dan mudah dilakukan namun dapat mengakibatkan pencemaran terhadap lingkungan, salah satunya adalah terbentunya air lindi (leachate) [1]. Air Lindi (leachate) adalah cairan yang timbul dari hasil dekomposisi biologis sampah yang telah membusuk yang mengalami pelarutan akibat masuknya air eksternal ke dalam timbunan sampah.

Tempat Pemrosesan Akhir (TPA) Bukit Pinang di Kota Samarinda merupakan salah satu TPA yang menerapkan sistem open dumping pada areal seluas $\pm 95.000 \mathrm{~m}^{2}$ (pen). TPA ini menampung $566.928,15 \mathrm{~m}^{3}$. Tingginya suhu, kelembaban dan curah hujan di Kota Samarinda [2] menyebabkan proses pembusukan pada sampah organik menjadi lebih cepat yang selanjutnya bercampur dengan air hujan membentuk lindi yang dapat mencemari lingkungan air bawah tanah. 


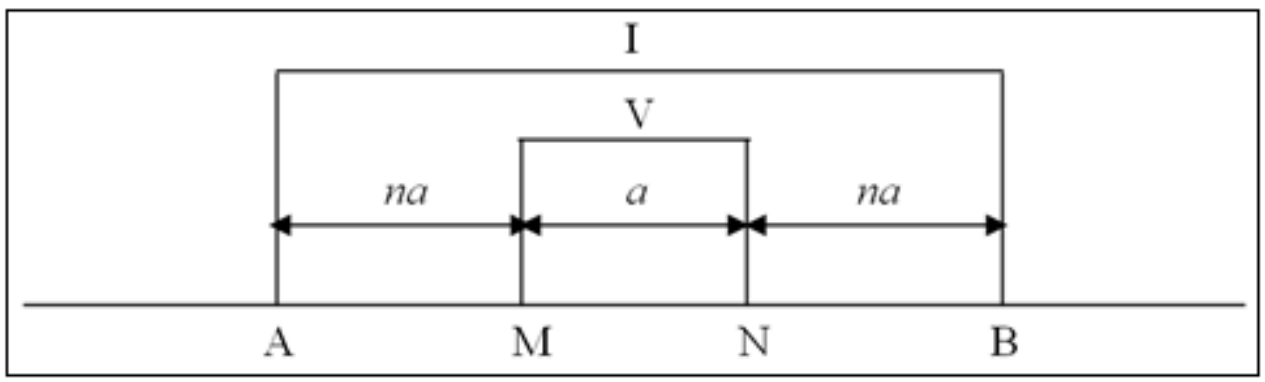

Gambar 1. Konfigurasi Schlumberger

Lindi merupakan polutan yang mengandung ion-ion logam berat yang cenderung memiliki tahanan jenis (resistivitas) lebih rendah dibandingkan dengan air bawah tanah. Selain itu Lindi sebagai polutan yang mengandung komponen fisik dan kimia tertentu juga memiliki sifat chargeability tertentu. Oleh karenanya potensi keberadaan lindi dapat diamati dengan melakukan pengukuran resistivitas $[3,4]$ dan chargebility [5] sistem yang ditinjau.

Pencemaran air bawah tanah merupakan problem besar mengingat air merupakan kebutuhan hajat hidup masyarakat. Pencemaran yang meresahkan masyarakat dunia adalah pencemaran yang disebabkan sampah yang jumlahnya terus meningkat seiring dengan peningkatan jumlah penduduk [6]. Penanganan terhadap pencemaran dapat dilakuan dengan tepat jika diketahui keadaan pencemaran yang ada, termasuk adanya potensi lindi di sekitar TPA. Dengan demikian dilakukan penelitian dengan tujaun mengetahui potensi lindi di daerah lingkungan TPA Bukit Pinang di Kota Samarinda.

\section{Resistivitas dan Rechargibility}

Lapisan batuan yang mengandung air terkontaminasi lindi memiliki tahanan jenis (resistivitas) kurang dari $10 \Omega$.m. Gambar 1 memperlihatkan, jika terdapat dua elektroda arus listrik berlawanan polaritas dan dua elektroda potensial listrik yang diinjeksikan pada dua titik arus di permukaan bumi homogen, maka potensial listriknya diperoleh dari beda potensial listrik antara VM dan VN. Dapat dijelaskan bahwa $M N=a$ dan $\mathrm{AM}=\mathrm{NB}=$ na, sehingga didapatkan persamaan resistivitas semu untuk konfigurasi schlumberger sebagai berikut.

$$
\rho_{\mathrm{as}}=n(n+1) \pi a \frac{\Delta V}{I}
$$

dalam hal ini $\rho_{\text {as }}$ adalah resistivitas semu konfigurasi schlumberger ( $\left.\Omega . \mathrm{m}\right), n$ adalah faktor pembesaran spasi elektroda, $a$ adalah spasi elektroda terkecil $(\mathrm{m}), \Delta V$ adalah beda potensial listrik $(\mathrm{mV})$ dan $I$ merupakan kuat arus listrik (mA).

Lindi sebagai polutan yang mengandung komponen fisik dan kimia tertentu juga memiliki sifat chargeability tertentu. Air tanah dengan salinitas tinggi (bersifat asin) memiliki nilai chargeability negatif $(<0 \mathrm{msec})$ [5]. Salah satu metode yang dapat digunakan untuk mengolah data geolistrik resistivitas dan chargeability adalah pemodelan inversi. Pemodelan inversi merupakan suatu metode yang digunakan dalam interpretasi komputer untuk memodelkan suatu data secara otomatis untuk mendapatkan suatu model atau suatu nilai yang dicari.

\section{Metode Penelitian}

Penelitian ini dilakukan di areal sekitar TPA Bukit Pinang Kota Samarinda Kelurahan Air Putih Kecamatan Samarinda Ulu Kota Samarinda. Alat-alat yang digunakan dalam penelitian adalah total station, global position system (GPS), kompas-klinometer, meteran, resistivity meter (multichannel), sumber arus DC (accu) 12 V 35 A, 48 elektroda (stain lees steel), 2 roll kabel penghubung elektroda (multicore)

Peninjauan karakteristik geologi dilakukan dalam bentuk pengukuran kedudukan dan deskripsi lapisan batuan yang tersingkap di sekitar TPA. Pemetaan karakteristik geomorfologi dilakukan dalam 


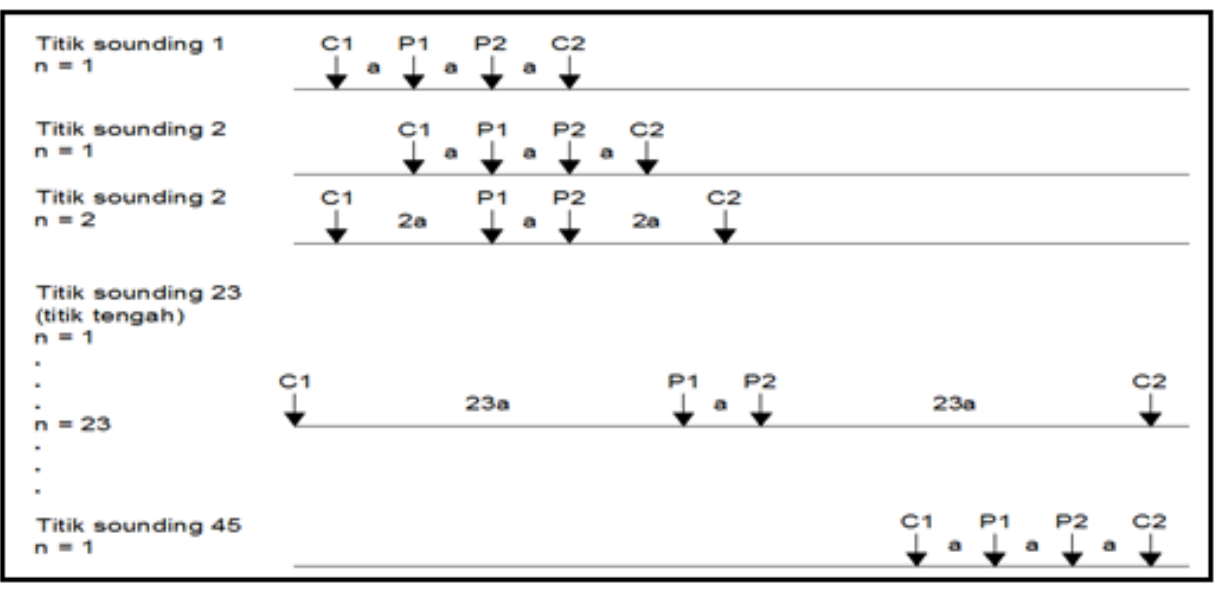

Gambar 2. Model lintasan pengukuran konfigurasi Schlumberger

bentuk pengukuran topografi dan profil topografi lintasan geolistrik. Pemetaan topografi dilakukan untuk mendapatkan gambaran tentang potensi areal limpasan lindi yang bersumber dari TPA. Pengukuran profil lintasan geolistrik dilakukan untuk memperoleh data dalam mengatur spasi elektroda.

Pengukuran nilai-nilai variabel geolistrik lapisan batuan dilakukan dengan metode geolistrik konfigurasi schlumberger menggunakan alat geolistrik MAE tipe X612-EM. MAE tipe X612-EM merupakan alat ukur multichannel yang dilengkapi dengan 48 elektroda. Pengukuran dilakukan di setiap titik sounding dengan spasi antar elektroda potensial tetap dan spasi antar elektroda potensialarus na. Spasi a terkecil adalah 4 meter yang diperbesar maximum $n$ kali faktor pembesaran pada setiap line (line A sampai dengan line H) seperti yang ditunjukan pada Gambar 2.

Dalam proses pengukuran geolistrik, nilai-nilai resistivitas semu $\left(\rho_{\mathrm{a}}\right)$ dan chargeability semu (ma) dapat langsung diproses dan dihitung.Nilai yang dihitung didasarkan pada nilai variabel-variabel yang diukur yakni beda potensial $(\Delta V)$, kuat arus $(I)$, peluruhan potensial $\left(V_{\mathrm{s}}\right)$ dan domain waktu $(t)$.

Selanjutnya, nilai-nilai resistivitas semu $\left(\rho_{\mathrm{a}}\right)$ dan chargeability semu (ma) dihitung menggunakan program res2dinv, untuk mendapatkan gambaran (peta) tentang sebaran air tanah dangkal terkontaminasi lindi dalam tampilan 2-D (dua dimensi) [4]. Hasil dari pengolahan program res2dinv akan dianalisis untuk memperoleh kedalaman dan ketebalan lapisan air tanah dangkal terkontaminasi lindi. Kemudian, data-data kedalaman dan ketebalan tersebut digunakan untuk memodelkan sebaran air tanah dangkal terkontaminasi lindi dalam tampilan 3-D (tiga dimensi) menggunakan program surpac.

\section{Hasil dan Pembahasan}

\subsection{Hasil Analisis Geomorfologi dan Geologi}

Berdasarkan hasil pengukuran topografi, lokasi penelitian (TPA Bukit Pinang dan sekitarnya) memiliki dua satuan geomorfologi yakni satuan perbukitan bergelombang sedang sampai terjal dan satuan dataran. Kedua satuan geomorfologi tersebut memiliki pengaruh dalam proses limpasan dan proses infiltrasi air lindi ke dalam tanah.

Limpasan di sekitar TPA dibedakan menjadi dua zona sumber limpasan. Zona pertama, air lindi yang berasal dari TPA langsung melimpas pada daerah di sekitarnya karena tidak memiliki drainase di sekitarnya, dimana pada area tersebut terdapat lintasan geolistrik line A, B, C, D, E dan G. Zona kedua, memiliki peluang yang kecil akan terjadinya limpasan air lindi dari TPA karena terdapat drainase di sekitarnya. Limpasan akan terjadi jika intensitas curah hujan tinggi sehingga volume limpasan lebih besar dari volume tampungan drainase dalam waktu tertentu, dimana pada area tersebut terdapat lintasan geolistrik line D, E, F, G dan H. 


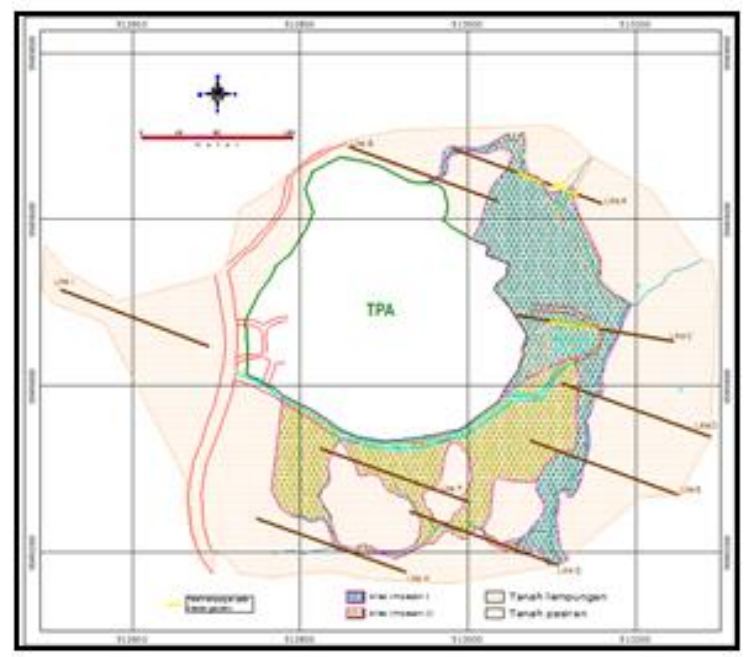

Gambar 3. Peta sebaran lapisan penutup di sekitar TPA Bukit Pinang Kota Samarinda

Dari hasil peninjauan, lokasi TPA Bukit Pinang dan sekitarnya memiliki kedudukan $\pm \mathrm{N} 20 \mathrm{E} / 70^{\circ}$ terdiri dari lapisan batupasir, lapisan batulempung, lapisan batupasir lempungan dan lapisan batulempung pasiran yang ditutupi lapisan penutup berupa tanah pasiran dan tanah lempungan.

Berdasarkan Gambar 3, diyakini letak lintasan pengukuran geolistrik berada pada daerah yang memiliki lapisan penutup tanah pasiran. Lintasan geolistrik dengan lapisan penutup tanah lempungan hanya berada di line A dan line C. Umumnya, tanah pasiran memiliki nilai porositas dan kapasitas infiltrasi yang lebih besar dari pada tanah lempungan, dengan demikian, sebaran tanah lempungan pada lintasan geolistrik line A dan $\mathrm{C}$ memiliki kapasitas infiltrasi lebih rendah dibandingkan dengan lintasan geolistrik lainnya.

\subsection{Pola Penyebaran Indikasi Air Tanah Dangkal Terkontaminasi Lindi di Sekitar TPA Bukit Pinang Kota Samarinda}

Hasil pemodelan inversi menunjukkan bahwa indikasi akumulasi lindi berada pada line A sampai line $\mathrm{H}$ sedangkan pada line I tidak terdapat indikasi akumulasi lindi. Dari gambar 4. menunjukkan bahwa keberadaan akumulasi lindi pada line A sampai H ditunjukkan oleh sebaran nilai resistivitas $0,78 \Omega . m$ sampai $9,37 \Omega . m$ dan sebaran nilai chargeability $-43,7 \mathrm{msec}$ sampai $-0,56 \mathrm{msec}$ pada kedalaman 0 meter sampai 26.39 meter dengan ketebalan 0,18 meter sampai 24,5 meter.

Berdasarkan hasil analisis pada line A sampai dengan line $\mathrm{H}$ tersebut, diperoleh model tiga dimensi (3-D) sebaran indikasi air tanah dangkal terkontaminasi lindi di sekitar TPA yang ditunjukkan pada gambar 4. Keberadaan indikasi air tanah dangkal terkontaminasi lindi tersebut tersebar dan terakumulasi di bagian utara, timur dan selatan TPA. Pola sebaran indikasi air tanah dangkal terkontaminasi lindi di bagian utara dan selatan TPA cenderung mengikuti pola jurus (strike) lapisan batuan (N 20 E). Pada bagian timur TPA, cenderung mengikuti pola jurus (strike) lapisan batuan dan pola aliran sungai.

Sebaran indikasi air tanah dangkal terkontaminasi lindi di bagian utara TPA terdiri dari 7 akumulasi lindi dengan kedalaman 0-13,58 meter dan ketebalan 0,36-21,64 meter. Adapun indikasi akumulasi lindi dalam air tanah dangkal yang terbentuk bersumber dari rembesan lindi yang bergerak ke arah utara TPA dan bersumber dari limpasan lindi yang terinfiltrasi.

Sebaran indikasi air tanah dangkal terkontaminasi lindi di bagian selatan TPA terdiri dari 16 akumulasi lindi dengan kedalaman 0,00-26,39 meter dan ketebalan 0,18-24,50 meter. Indikasi akumulasi lindi dalam air tanah dangkal F1, F2, F3, F4, F5, F6 dan H1 tersebar dengan pola mengikuti pola jurus (strike) lapisan batuan. Indikasi akumulasi lindi dalam air tanah dangkal F7-G1, G2, G3, G4, G5, G6, H2, H3 dan H4 tersebar pada endapan dataran banjir. Adapun indikasi 


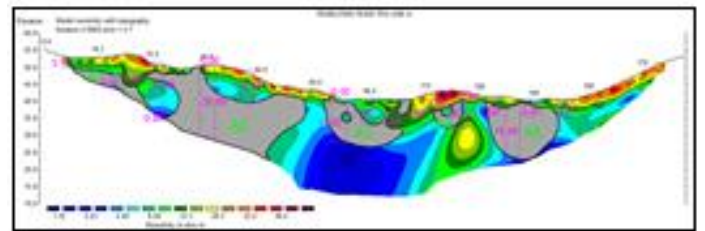

A

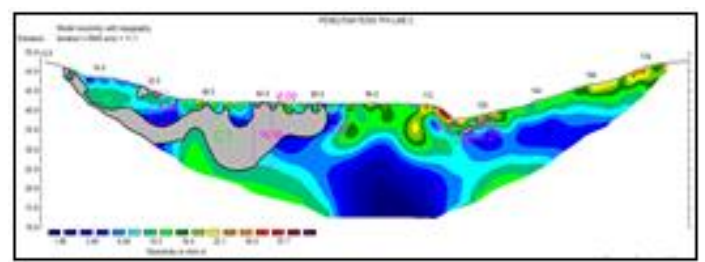

$\mathrm{C}$

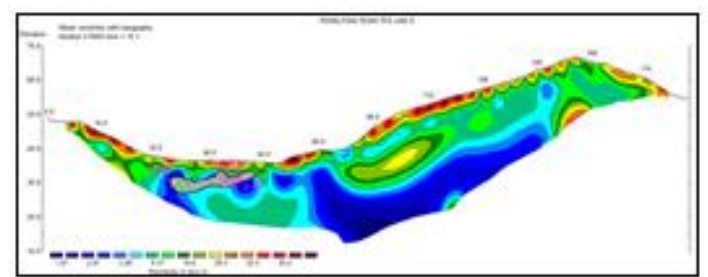

$\mathrm{E}$

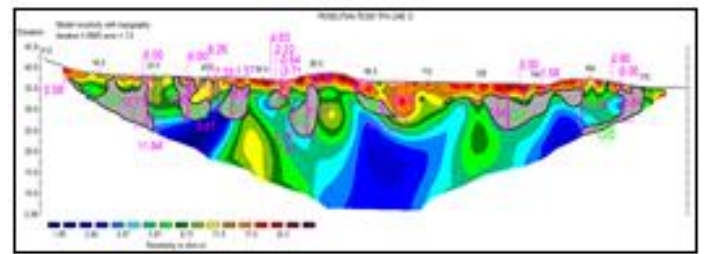

G

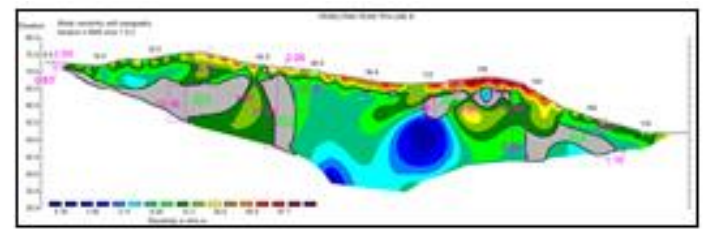

B

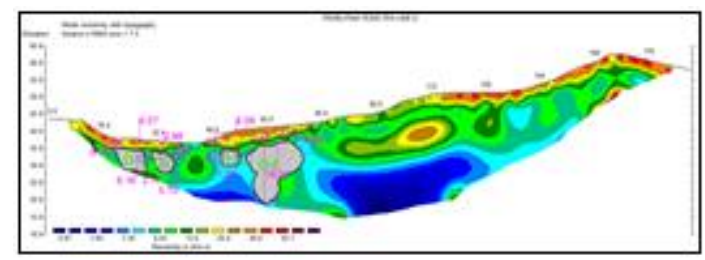

$\mathrm{D}$

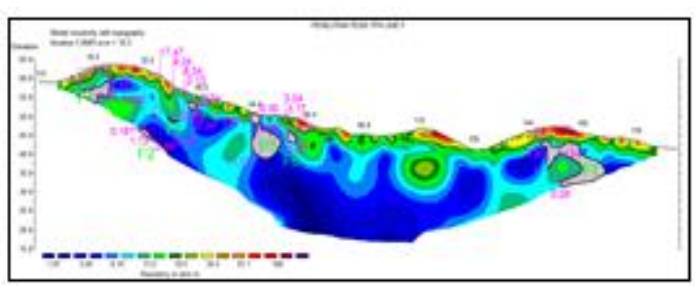

$\mathrm{F}$

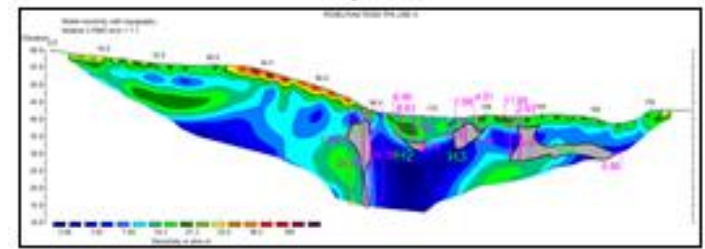

$\mathrm{H}$

Gambar 4. Hasil pemodelan inversi

akumulasi lindi dalam air tanah dangkal yang terbentuk bersumber dari rembesan lindi yang bergerak ke arah selatan TPA dan bersumber dari limpasan lindi yang terinfiltrasi.

Berbeda dengan bagian di sekitar TPA lainnya, bagian barat TPA Bukit Pinang yang diteliti pada lintasan I menunjukkan bahwa tidak terdapat indikasi sebaran lindi. Gambar 6 menunjukkan bahwa dari karakteristik geomorfologi, areal sebelah barat TPA berada pada lereng yang dibatasi oleh punggung bukit dengan elevasi lebih tinggi dari pada posisi TPA dengan demikian area bagian barat TPA bebas dari limpasan lindi yang berasal dari TPA. Dari karakteristik geologi, batuan pada lokasi penelitian memiliki kedudukan $\pm \mathrm{N} 20^{\circ} \mathrm{E} / 70^{\circ}$ dengan kemiringan lapisan batuan cenderung ke arah timur. Salah satu lapisan batuan pada lokasi penelitian yang bersifat impermeabel adalah batulempung. Indikasi keberadaan batulempung dapat menjadi pembatas sebaran air tanah dangkal terkontaminasi lindi ke arah barat TPA.

Dari hasil pemodelan geolistrik dua dimensi (2-D) dan pemodelan tiga dimensi (3-D) menunjukkan bahwa terdapat beberapa ketidaksesuaian antara pola penyebaran hasil pemodelan dengan pola perlapisan batuan pada lokasi penelitian. Menurut penulis, pola penyebaran air tanah 


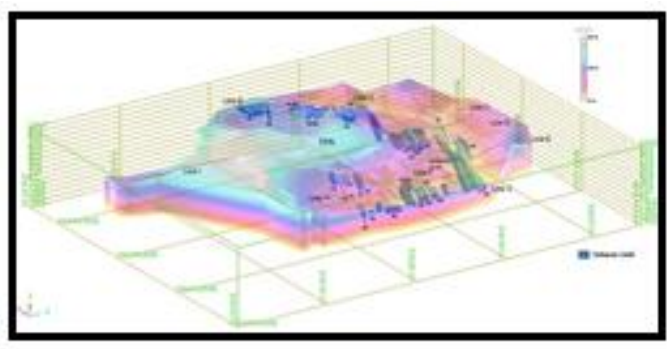

(a)

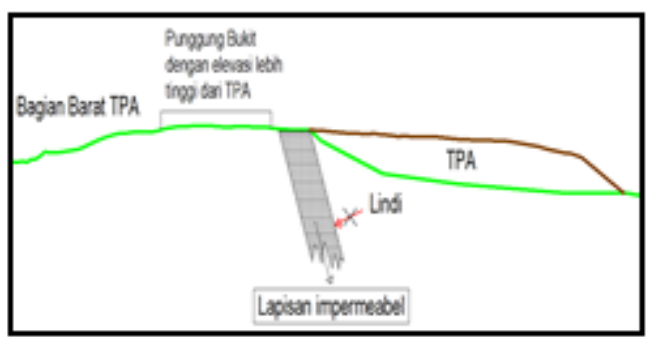

(b)

Gambar 5. Model tiga dimensi (3-D) sebaran indikasi air tanah dangkal terkontaminasi lindi di sekitar TPA tampak barat daya-timur laut

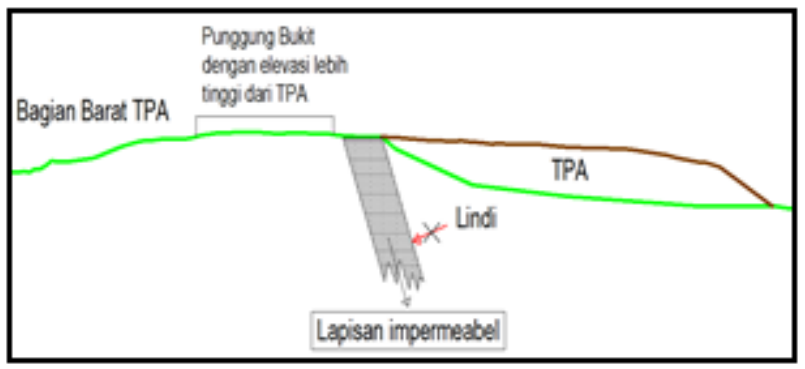

Gambar 6 Pengaruh karakteristik geomorfologi dan geologi terhadap sebaran lindi di bagian barat TPA

dangkal terkontaminasi lindi yang ditampilkan oleh hasil pemodelan sangat dipengaruhi oleh 3 faktor yakni karakteristik geologi, sebaran data resistivitas dan chargebility serta sebaran konsentrasi lindi.

Dampak sebaran lindi di sekitar TPA Bukit Pinang adalah tercemarnya air sumur pada lingkungan masyarakat yang bermukim di bagian utara, timur dan selatan TPA dengan segala aktivitasnya tentu memiliki peluang untuk dikontaminasi oleh lindi, baik secara langsung maupun secara tidak langsung. Kontaminasi langsung dapat terjadi melalui pemanfaatan air tanah dangkal terkontaminasi lindi melalui sumur-sumur dangkal sedangkan kontaminasi tidak langsung dapat terjadi melalui konsumsi hasil tanam tumbuh yang menyerap air tanah dangkal terkontaminasi lindi pada zona perakaran dan daging hewan ternak yang mengkonsumsi air dari sumur dangkal dan melalui rantai makanan. Oleh karenanya perlu adanya usaha-usaha penaggulangan yang dilakukan baik oleh instansi-instansi terkait maupun pihak-pihak berkompeten lainnya dalam menangani masalah ketidakseimbangan lingkungan di sekitar TPA Bukit Pinang Kota Samarinda.

\section{Kesimpulan dan Saran}

Berdasarkan hasil analisis dan pembahasan yang telah dilakukan, maka diperoleh kesimpulan sebagai berikut.

1.) Sistem pengelolaan sampah dan kondisi fisik instalasi pengelolaan air limbah pada TPA Bukit Pinang Kota Samarinda berpotensi menimbulkan indikasi pencemaran air lindi air di sekitar TPA.

2.) Karakteristik geologi dan geomorfologi pada TPA Bukit Pinang Kota Samarinda berperan besar sebagai faktor pendukung terhadap pembentukan indikasi pencemaran terhadap air tanah dangkal di sekitar TPA melalui proses limpasan dan infiltrasi.

3.) Hasil pemodelan geolistrik menunjukkan adanya indikasi air tanah dangkal terkontaminasi lindi dari line A sampai line $H$ dengan sebaran nilai resistivitas 0,78 $\Omega$.m sampai 9,37 $\Omega$.m dan sebaran nilai chargeability $-43,7$ msec sampai $-0,56$ msec pada kedalaman 0 meter sampai 26.39 meter dan ketebalan 0,18 meter sampai 24,5 meter. Indikasi air tanah dangkal terkontaminasi lindi tersebar di bagian utara, timur dan selatan sampai jarak sejauh 180 meter dari pinggir TPA Bukit 
Pinang Kota Samarinda dengan pola sebaran mengikuti jurus (strike) lapisan batuan (N 20 E) dan pola aliran sungai di bagian timur.

\section{Daftar Rujukan}

[1] S. M. Ali, et. al (2014), Open Dumping of Municipal Solid Waste and Its Hazardous Impacts on Soil and Vegetation Diversity at Waste Dumping Sites of Islamabad City, Journal of King Saud University - Science 26, 59-65

[2] W. Ambarwulan, 2010, Remote Sensing of Tropical Coastal Waters: Study of The Berau Estuary, East Kalimantan, Indonesia, ITC dissertation number 173, University of Twente, The Netherlands.

[3] Ngadimin and Handayani G. 2000. "Aplikasi Metode Geolistrik Untuk Alat Monitoring Rembesan Limbah" Journal of Mathematical Science. Vol.2 No. 06

[4] Loke, M.H, (1999b), 2D Resistivity \& IP Inversion Suppor Land and Underwater Surveys; Res2dinv ver. 3.2 for Windows 3.1 and 95. Malaysia: Penang.

[5] Zera, T. and Nurmilasari, (2010), "Penentuan Lapisan Air Tawar dan Air Asin di Daerah Kudus dengan Metode Geolistrik Polarisasi Terimbas" Prosiding Seminar Nasional Fisika 2010. Jakarta.

[6] G.S.R. Karishnamurti, R. Naidu, (2003), Solid-Solution Equilibria Of Cadmium In Soils Geoderma, 113, 17-30 